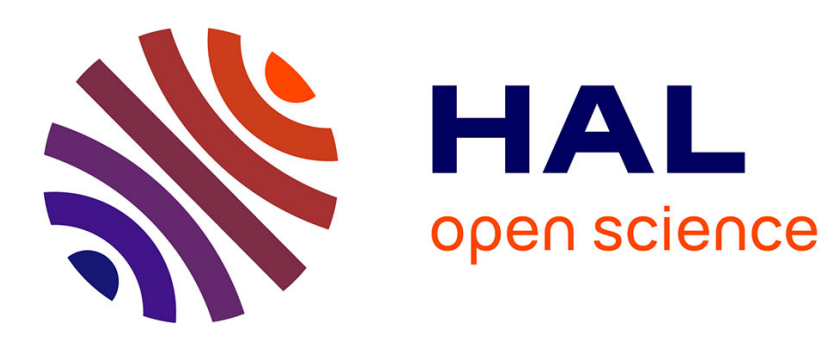

\title{
What did we recently learn about the evaluation of energy efficiency policies and programmes? Insights from IEPPEC 2014 in Berlin
}

\author{
Jean-Sébastien Broc, Catherine Cooremans
}

\section{- To cite this version:}

Jean-Sébastien Broc, Catherine Cooremans. What did we recently learn about the evaluation of energy efficiency policies and programmes? Insights from IEPPEC 2014 in Berlin. Energy efficiency, 2016, 9 (4), pp.843-846. 10.1007/s12053-016-9457-4 . hal-01577517

HAL Id: hal-01577517

https://hal.science/hal-01577517

Submitted on 25 Aug 2017

HAL is a multi-disciplinary open access archive for the deposit and dissemination of scientific research documents, whether they are published or not. The documents may come from teaching and research institutions in France or abroad, or from public or private research centers.
L'archive ouverte pluridisciplinaire HAL, est destinée au dépôt et à la diffusion de documents scientifiques de niveau recherche, publiés ou non, émanant des établissements d'enseignement et de recherche français ou étrangers, des laboratoires publics ou privés. 
Title:

What did we recently learn about the evaluation of energy efficiency policies and programmes? Insights from IEPPEC 2014 in Berlin

\title{
Authors:
}

Jean-Sébastien Broc, Broc Research \& Consulting, jsb@brnc.fr

Catherine Cooremans, Université de Genève, catherine.cooremans@ unige.ch

\begin{abstract}
:
This short communication introduces the special issue based on a selection of papers first presented at the International Energy Policy \& Programme Evaluation Conference in Berlin on 9 to 11 September 2014.
\end{abstract}

Keywords: evaluation, energy efficiency policies 
The International Energy Policy \& Programme Evaluation Conference (IEPPEC) held in Berlin in September 2014 was the third conference organised in Europe after Paris in 2010 (see Vine and Thomas, 2012) and Rome in 2012. These conferences were first organised with the same name as the US conference (IEPEC, International Energy Program Evaluation Conference) held in the US every two years since 1989. This name was changed for the Berlin conference to reflect the focus on policy evaluation that is more important in the European than in the US perspective, due to the differences in the regulatory context for energy efficiency activities on both sides of the Atlantic (Vine et al., 2013).

About 180 participants from 28 countries attended the Berlin conference that included the presentation of 78 papers (see the full proceedings available at: http://www.ieppec.org/proceedings/berlin/ ). These papers provide a rich overview of the latest developments in evaluation methodologies and practices, together with very useful experience feedback.

This Special Issue includes a subset of these papers, not meaning to be representative nor to provide a summary of the main discussions occurring at the conference. Our aim was to show the diversity of the issues covered, and to highlight particular topics relevant for further research. These papers were selected based on suggestions from the moderators of the sessions at the conference, and went through an additional review process before publication in the Energy Efficiency journal.

In terms of geographic coverage, these papers deal with the evaluation of energy efficiency policies or programs implemented in 6 different countries: Belgium (Ruelle), France (Raynaud), Ireland (Stanley), Japan (Mukai), the Netherlands (Harmsen) and the United States (Dougherty and Storm). Moreover, Ajanovic deals with policies implemented at the level of the European Union.

Most of the papers are focused on the residential or buildings sector (Dougherty, Mukai, Raynaud, Ruelle, Stanley, Storm), while only one paper deals with transports (Ajanovic). Industry is not addressed in this Special Issue. The higher share of papers on buildings was intentional in the selection, as improving the energy efficiency of existing buildings is a clear priority of European energy efficiency policies (see for example the article 4 of the Energy Efficiency Directive about national renovation strategies).

Raynaud, Ruelle, Stanley and Storm look at very different programmes or policy instruments, offering complementary views on key issues when promoting retrofitting actions to improve energy efficiency in buildings. Raynaud enters into the details of impacts on energy consumption of refurbishment works. Ruelle provides a rich experience feedback about the test of an innovative approach to stimulate refurbishment works. Stanley examines the influence of one key information tool about energy efficiency of buildings (Energy Performance Certificates). And Storm presents a comprehensive evaluation of a market transformation programme for an innovative type of heat pumps.

In "Evidence of an indirect rebound effect with reversible heat pumps", Raynaud focuses on a specific part of an ex-post evaluation of a regional energy efficiency programme in the SouthEast of France. Combining a billing analysis and a survey makes possible to investigate 
households behaviours related to space heating and air conditioning, before and after refurbishment works. As the equipment rate of air conditioning is significantly growing in Europe, these results are a very interesting contribution to the literature, where such analysis has been rarely presented so far. The paper also provides a concrete case study discussing the concept of direct and indirect rebound effects. A pragmatic approach is used to propose an uncertainty analysis of the energy savings. This is often overlooked in evaluation studies, while it brings a better understanding of the results. The statistical analysis confirms a result observed in similar billing analyses that the energy consumption before retrofitting is the key explanatory variable of the energy savings dispersion. In this case study, the other key variable is the use of air conditioning after retrofitting, defined here as an indirect rebound effect due to the new service offered by a reversible heat pump. However this effect remains limited. Raynaud concludes by highlighting the difficulties to perform statistical analysis on pilot programmes, meaning a small sample size, while larger samples would be needed to draw stronger conclusions.

In "Guided group purchases of energy renovation services and works in deprived urban neighbourhoods", Ruelle reports an action research experimenting an innovative approach aiming at accelerating the retrofitting of existing dwellings by grouping within a Belgian neighbourhood the purchase of energy renovation services (in particular energy audits) and works. While the participants initially expected costs reduction from this approach, they also saw as key benefits the guidance, the facilitation with contractors and the social dynamics created. Further investigation would be needed to scale up this approach, in particular for increasing the involvement of the construction industry (through contacts with its federations), of the main landlords and of local authorities. The role of the organisers (for grouping purchases) is key, and requires knowledge (and therefore training) about the technical, financial and legal aspects. This paper shows the interest and added value of a close coordination between the implementation and the evaluation team from the design of the initiative. This delivers a detailed understanding of the approach used, its impacts, benefits and limitations. All these lessons learnt are essential for further dissemination.

In "The price effect of building energy ratings in the Dublin residential market", Stanley looks at one of the main tools of the EPBD (EU Energy Performance of Buildings Directive): the Energy Performance Certificate (EPC, named energy performance rating in Ireland). Using an econometric approach (with a hedonic model), Stanley examines the influence of EPC on the prices of dwellings in the Dublin housing market. The results show a significant positive impact of the EPC (higher energy efficiency leads to higher price of the property). The paper also highlights the importance of the variables taken into account in the model. These results confirm the conclusions from similar recent research about the "green value" of energy efficiency. Further research would then be needed to investigate if this provides a sufficient incentive or driver for the implementation of energy efficiency actions by landlords.

In "Northwest ductless heat pump Pilot Project - a holistic approach to market transformation and evaluation", Storm provides a rich experience feedback from a comprehensive and integrated evaluation. The case study is a programme led in the Northwest of the US to promote Ductless Heat Pumps (DHP), using a holistic approach aiming at market transformation. The evaluation combined interviews with the stakeholders and participants, laboratory testing, field monitoring, billing analysis and finally a cost-effectiveness analysis. This represents an 
exemplary case with a complete analysis based on a multi-perspective approach. The solution promoted by the programme was new to the market, which required this detailed understanding of the energy savings impacts, as well as the market acceptance. This approach proves to be very relevant to support a long term strategy, which is essential if energy efficiency is to be considered seriously as a resource or one of the main fuels for the energy mix.

The majority of the papers selected in this Special Issue is about policies or programmes promoting technical actions (heating systems and building insulation for Raynaud and Ruelle, heat pumps for Storm, cars for Ajanovic). Two papers (Dougherty and Mukai) focus on behavioural actions or changes, which was noted as one of the key emerging evaluation issues in Vine et al. (2013).

In "Behavioral Energy Feedback Program Evaluations", Dougherty analyses key issues raised by the strong development of behavioural-based programmes in the energy efficiency portfolios of US utilities, through a review of available evaluations for this type of "feedback" programmes. The paper highlights existing gaps knowledge and formulates research questions requiring further investigations. The conclusions point out the over-focus on impact evaluations, while little is known about how behavioural programme actually generate energy savings. This observation was also made during the session "Ex-Post Evaluations for utility Programs: Providing Facts \& Figures" at the conference. Statistical methods can tell whether changes in energy consumption are statistically significant. However, they cannot tell why these changes occurred, unless surveys are made to look at the actions implemented. Dougherty's paper also shows how tricky it can be to combine results from evaluations using different evaluation methods or assumptions.

In "Energy Efficiency Evaluating a Behavioral Demand Response Trial in Japan", Mukai presents results from a behavioural demand response trial targeted at both grid and residential peak hours during the Summer of 2013. In the trial, four different intervention packages were used to communicate with 230 residential customers of a condominium in Funabashi (Greater Tokyo). Through a randomized experiment, Mukai finds that the peak saving impact during grid peak hours (1-4pm, weekdays only) were about $11 \%$. Their results also show that household characteristics do influence variation in peak savings and that the variation differs among packages of peak saving interventions. Mukay concludes that feedback for peak saving can promote households' energy conservation behaviour. The originality of this experimentation lies in using feedback for demand-response purposes, while this has been most often used for energy conservation, as shown in the meta-evaluation by Dougherty.

Most of the papers are based on impact evaluations, either ex-ante (Ajanovic) or ex-post (Mukai, Osso, Stanley, Storm). And Dougherty presents a review of impact evaluations. None of the paper is explicitly focused on process (or theory-based) evaluation, but this is often embedded in the impact evaluation to some extent. We chose to give a priority to impact evaluations in this Special Issue, because there is a critical need for more evidences about energy savings achieved: many countries are committing to more ambitious energy savings targets and the European Commission pointed out the need for more investments in energy efficiency to achieve these targets (see for example: http://ec.europa.eu/energy/node/1742 ). Conclusions from impact evaluations, and in particular from ex-post evaluations, are essential to ensure that these investments are made in an effective way. 
Ex-ante evaluations can also be very helpful for improving policy design, as shown by Ajanovic in "Reducing CO2 emissions of cars in the EU". Ajanovic analyses how different policy instruments (mainly $\mathrm{CO} 2$ emissions standards, registration taxes and fuel taxes) may influence the purchase decision and the use of cars. This theoretical analysis brings additional understanding of the underlying mechanisms of the policy instruments, which can help policy design by reinforcing the policy theory and identifying key assumptions to test in order to monitor the actual effectiveness of the policy instruments. Ajanovic uses the concept of service price elasticity to show the interlinkage between $\mathrm{CO} 2$ emissions standards (or registration taxes) and fuel taxes, and how they could be combined to limit the risk of rebound effect and therefore be more effective to reduce $\mathrm{CO} 2$ emissions. This is a major conclusion from this research, which could be complemented further by considering variables explaining differences in behaviours according to different households' categories. The paper provides also a useful overview about the differences in tax levels among the European countries.

In addition, two papers focus on two key methodological issues for any type of evaluation. Batey questions the current evaluation practices by looking at how ICT (Information and Communication Technology) could be used for do-it-yourself data collection to develop new evaluation approaches. While Harmsen looks at the influence of the indicator used to set targets. Both papers deal with important debates for the evaluation community.

ICT, for example through the roll-out of communicating energy meters (but not only!), are changing the conditions and the approaches for data collection. This should dramatically increase the quantity of data available, raising many issues. In "From calculated to real energy savings performance evaluation", Batey looks at the issue of data collection, which is in particular critical when evaluating the impacts of policies or programmes promoting energyefficient behaviour change. Based on a rich literature review and case studies done for the International Energy Agency (IEA) Demand Side Management Implementing Agreement Task 24 (Behaviour Change), they point out the reasons behind the lack of measured data monitoring. From these observations, they propose to change the data collection process from a centralised monitoring to a user-centred data delivery, taking advantage of the ICT potentialities. This raises very interesting discussions about the risks to privacy and security, the use and ownership of the data. This is indeed a key debate at the time where communicating energy meters are rolled out in an increasing number of countries. The proposed approach is here to promote "horizontal" data management across peer systems instead of "vertically" aggregating data. One of the main advantages of this approach is that users would retain control over their data. The paper also highlights some limitations of participatory approaches (e.g., labour-intensive approach, lack of real political support hence lack of budget), and suggests that social media could help tackle them. Batey's contribution will very likely stimulate further investigation and experimentations.

At the other side of data management, the definition of the indicators used to analyse the data is also a key methodological issue. Harmsen questions the choice of using final energy when setting the metric of targets for the development of renewable energy sources (RES). The paper uses the example of the main Dutch support scheme for RES to analyse how choosing final energy instead of primary energy could deliver a misleading signal, in case of a scheme with budget limitation and short term objectives. Beyond the focus on the metrics used for the target 
indicator, the results presented in the paper raise more broadly the risks of using a too narrow definition of cost-effectiveness when designing a scheme to promote a least cost approach.

Last but not least, other papers presented at the Berlin conference have been developed by their authors to be published in journals (Braungardt et al., 2016 ; De Schepper et al., 2015 ; Nauleau, 2014 ; Quitzow, 2015 ; Rietbergen et al., 2016 ; Smedby, 2016 ; Suerkemper et al., 2015). This is also a good indicator about the quality of the conference proceedings.

\section{Acknowledgements}

We would like to thank very much Paolo Bertoldi and the Springer team for making this special issue possible, all the moderators of IEPPEC 2014 for helping us in selecting the papers, all the authors for accepting an additional review process on their papers, and all the reviewers who contributed to ensuring the quality of this special issue.

\section{References}

Braungardt, S., Elsland, R., Eichhammer, W., 2016. The environmental impact of ecoinnovations: the case of EU residential electricity use. Environmental Economics and Policy Studies, 18(2), 213-228.

De Schepper, E., Lizin, S., Durlinger, B., Azadi, H., Van Passel, S., 2015. Economic and Environmental Performances of Small-Scale Rural PV Solar Projects under the Clean Development Mechanism: The Case of Cambodia. Energies, 8(9), 9892-9914.

Nauleau, M. L., 2014. Free-riding on tax credits for home insulation in France: An econometric assessment using panel data. Energy Economics, 46, 78-92.

Quitzow, R., 2015. Assessing policy strategies for the promotion of environmental technologies: A review of India's National Solar Mission. Research Policy, 44(1), 233-243.

Rietbergen, M. G., Opstelten, I. J., Blok, K., 2016. Improving energy and carbon management in construction and civil engineering companies-evaluating the impacts of the $\mathrm{CO} 2$ Performance Ladder. Energy Efficiency, 1-25.

Smedby, N., 2016. Assessing local governance experiments for building energy efficiency-The case of Malmö, Sweden. Environment and Planning C: Government and Policy, 34(2), 299319.

Suerkemper, F., Thema, J., Thomas, S., Dittus, F., Kumpaengseth, M., Beerepoot, M., 2015. Benefits of energy efficiency policies in Thailand: an ex-ante evaluation of the energy efficiency action plan. Energy Efficiency, 1-24.

Vine, E., Hall, N., Keating, K. M., Kushler, M., Prahl, R., 2013. Emerging evaluation issues: persistence, behavior, rebound, and policy. Energy Efficiency, 6(2), 329-339.

Vine, E., Thomas, S., 2012. Introduction. Energy Efficiency, 5, 3-4. 
